\title{
Microstructure, Dislocation Density and Thermal Expansion Behavior Using Thermo Elastic Models of Zircon Sand Reinforced as Cast ZA-27 Composites
}

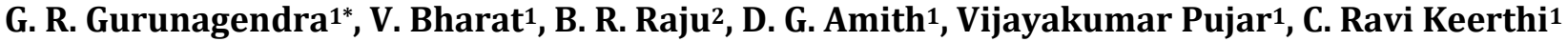 \\ ${ }^{1}$ Global Academy of Technology, Bangalore, India \\ ${ }^{2}$ The Oxford College of Engineering, Bangalore, India \\ Email: ^gurunagendra.gn@gmail.com
}

How to cite this paper: Gurunagendra, G.R., Bharat, V., Raju, B.R., Amith, D.G., Pujar, V. and Keerthi, C.R. (2021) Microstructure, Dislocation Density and Thermal Expansion Behavior Using Thermo Elastic Models of Zircon Sand Reinforced as Cast ZA-27 Composites. Journal of Minerals and Materials Characterization and Engineering, 9, 100-115.

https://doi.org/10.4236/jmmce.2021.91008

Received: November 23, 2020

Accepted: January 26, 2021

Published: January 29, 2021

Copyright ( 2021 by author(s) and Scientific Research Publishing Inc. This work is licensed under the Creative Commons Attribution International License (CC BY 4.0).

http://creativecommons.org/licenses/by/4.0/

\section{(c) (i) Open Access}

\begin{abstract}
In the present work stir casting route is used to fabricate the ZA27 Metal matrix composites containing $3 \mathrm{wt} \%, 6 \mathrm{wt} \%, 9 \mathrm{wt} \%$, and $12 \mathrm{wt} \%$. Zircon sand particulates of size 100 mesh. Microstructure studies using Optical Microscopy, SEM-EDAX are carried out to ascertain the distribution and morphology of particulates in the composites. Effect of zircon sand as reinforcement on bulk density, porosity, of the fabricated composites is studied. SEM studies are carried out to understand the behavior of as-cast ZA27 alloy reinforced with zircon sand. The dislocation density of the fabricated composite affects the strength of the composites and depends on the strain due to thermal mismatch and is found to increase with increase in weight\% of zircon sand. However, it does not consider casting defects of voids/clustering observed in micrographs of the fabricated composite. Porosity in composites does not have influence on Coefficient of thermal expansion (CTE) of the ZA27 composites studied using thermoelastic models like Kerner and turner model and rule of mixtures of composite.
\end{abstract}

\section{Keywords}

Density, Porosity, Dislocation Density, Thermoelastic Models, Rule of Mixtures

\section{Introduction}

Over the years, Metal matrix composites are playing a significant role in aerospace, automotive, space engineering and other industrial applications due to 
their superior mechanical, tribological and thermal properties.

Matrix is made of monolithic Metal or alloy and embedded with hard particulates to augment the properties of MMC compared to the monolithic metals/alloys. Aluminum, Magnesium, titanium, copper and Zinc based alloys are widely employed as matrix materials in various applications.

Over the past few decades research on zinc-based alloys are being carried out and found to exhibit excellent tribo-mechanical properties apart from low melting point, good cast ability and machinability. Several research have proved the Zinc-Aluminum family of alloys like ZA12 and ZA27 are possessing better strength when compared to cast-iron, bronze and plastics as tribo-elements for operating at moderate temperature condition. In spite of good tribo-mechanical properties The ZA alloy exhibits dimensional instability at temperature greater than $100^{\circ} \mathrm{C}$. With heat treatment techniques of cast alloy and addition of high melting point ceramic particles to the alloy the properties of the alloy can be improved at the expense of reduction in machinability which can be reduced by addition of dry lubricants [1] [2].

Nowadays researchers are inspired to reinforce these alloys with reinforcement particles and whiskers like $\mathrm{Al}_{2} \mathrm{O}_{3}$, Sic, Garnet, glass, Tic, graphite, Agri and industrial waste etc. to achieve better mechanical, wear and thermal characteristics. There are research reports of ZA27 alloy containing more than one reinforcement to produce hybrid composites like a ceramic filler and a solid lubricant like graphite to offset the negative effects of ceramic fillers on machinability [3] [4]. Also in recent times, researchers are adding nanofillers in recent times to the as-cast ZA27 alloy and fabricating the MMC using different metallurgical processes like, stir casting, double stir casting, squeeze casting, powder metallurgy and also ultrasonic-assisted stir casting for obtaining better casting and improved properties [3] [5]. There is not much work carried out on characterization of zircon sand reinforced with ZA27 alloy especially beyond 5\% weight fraction also micro-mechanical behavior of such composites [6]. Coefficient of thermal expansion (CTE) plays an important role in ZA27 materials used as tribo-elements and needs to be estimated for better performance of the elements. Thermoelastic models are used to predict the CTE of the ZA27/zircon sand composites [7]. Effects of presence of voids on dislocation density of composites and cracking/agglomeration of zircon particles in ZA27 matrix with increased weight fraction on CTE of composites and their effects on strength is addressed [8]. preparation of composites by various routes and its processing, matrixreinforcement bonding and characterization poses significant challenge in the end use of composites, also decrease in ductility, poor matrix-reinforcement interface, particle cracking, debonding/pull out of particles and agglomeration of particulates are some of the challenges in preparation of composites. composites are subjected to age hardening to obtain better strength and improved ductility as well as tribological properties [2] [9].

Stir casting is widely adopted route in preparing these composites due to their advantages like bulk manufacturing, ease of fabrication and economy. Also, 
there is enough scope to investigate and understand the behavior of ZA-27 containing microparticulate zircon sand as primary reinforcement and hybrid composites with dry lubricants as secondary reinforcement.

\section{Experimental Procedure (Figure 1 and Table 1)}

In this work Zircon sand $\left(\mathrm{ZrsiO}_{4}\right)$ of particle size 100 mesh is used as a primary reinforcement in the matrix of ZA-27. Chemical composition of Zircon sand is Zircon oxide and hafnium of $65 \%$ and silica of $24 \%$ with traces of $\mathrm{Al}_{2} \mathrm{O}_{3}, \mathrm{TiO}_{2}$ and $\mathrm{Fe}_{2} \mathrm{O}_{3}$ [10]. The thermal coefficients of zircon sand is low compared to other oxides of ceramics improving the interface strength, also the density of zircon sand $(\rho=4.56 \mathrm{~g} / \mathrm{cc})$ is in close proximity with the density of ZA-27 $(\rho=4.5 \mathrm{~g} / \mathrm{cc})$ alloy which reduces the problems of gravity segregation due to large density difference between matrix phase and dispersed phase (Figure 2 and Table 2).

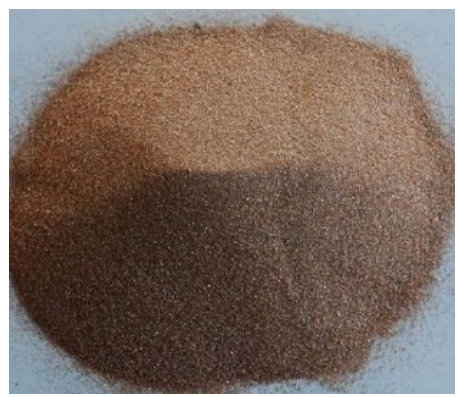

(a)

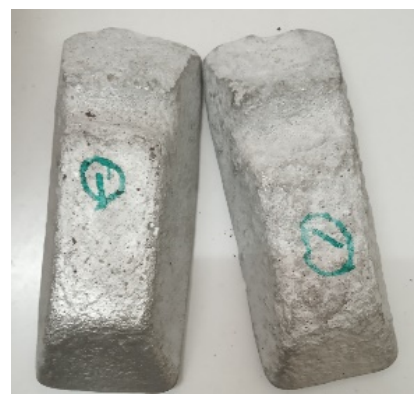

(b)

Figure 1. (a) Zircon sand particles (b) ZA-27 ingot.

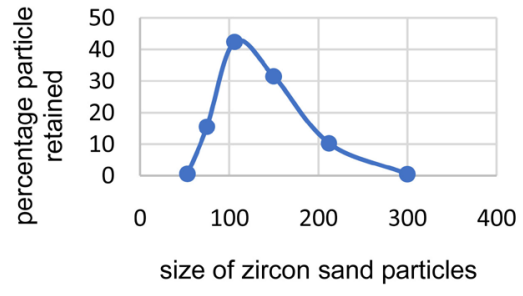

Figure 2. Particle size by sieve analysis.

Table 1. The chemical compositions of ZA-27 alloy.

\begin{tabular}{cccccc}
\hline $\mathrm{Al}$ & $\mathrm{Mg}$ & $\mathrm{Cu}$ & $\mathrm{Fe}$ & silicon & Zinc \\
\hline $\mathbf{2 5 . 6 0 \%}$ & $0.07 \%$ & $2.10 \%$ & $0.04 \%$ & 0.001 & Remainder \\
\hline
\end{tabular}

Table 2. Properties of zircon sand.

$\begin{array}{lc}\text { Melting point }\left({ }^{\circ} \mathrm{C}\right) & 2500 \\ \text { Hardness (Mohs) } & 7.5 \\ \text { Density }(\mathrm{g} / \mathrm{cc}) & 4.5 \\ \text { efficient of expansion }\left(10^{-6} \mathrm{~K}\right) & 4.5\end{array}$

crystal structure

Tetragonal 


\section{Preparation of ZA27 MMC by Stir Casting}

Composite was fabricated by stir casting method regarded as the most economical and suitable for mass production compared to other techniques of fabrication. The setup is as shown in Figure 3. To begin with the weight of reinforcements for $3 \mathrm{wt} \%, 6 \mathrm{wt} \%, 9 \mathrm{wt} \%$ and $12 \mathrm{wt} \%$ Zircon sand to prepare $2000 \mathrm{~g}$ of ZA-27 alloy was calculated. Zircon sand particles were preheated to around $200^{\circ} \mathrm{C}$ in an oven to remove presence of moisture in it ZA27 alloy ingots were placed in the graphite crucible and super-heated to a melting temperature and stirring was done for homogenizing temperature later the temperature was reduced to $450^{\circ} \mathrm{C}$ (semi solid state) Now, the reinforcement particles are fed a rate of $20 \mathrm{~g} / \mathrm{min}$ and the mixture with continued heating is stirred at a speed of $350 \mathrm{rpm}$ to create vortex for 5 minutes for better distribution of particles. $10 \mathrm{~g}$ of Magnesium rod was added to improve wettability and the melt is degassed using $\mathrm{C}_{2} \mathrm{Cl}_{6}$ (hex chloroethylene tablets) in order to eliminate porosity and remove air presence in the mixture. The composite was poured at $500^{\circ} \mathrm{C}$ into the preheated cast iron die for better solidification [6].

\section{Results and Discussion}

Theoretical density and experimental density of the base alloy and composite with different weight percentage of composite is evaluated. There will be difference in the values of densities due to the voids and pores generated during casting. Due to the presence of voids mechanical properties will get reduced so it is obvious to determine the density and porosity of the composites for ascertaining the quality of composites produced. Theoretical density is calculated using the rule of mixture,

$$
\rho_{\text {theoritical }}=\frac{100}{\sum_{i=1}^{n} \frac{x_{i}}{p_{i}}}
$$

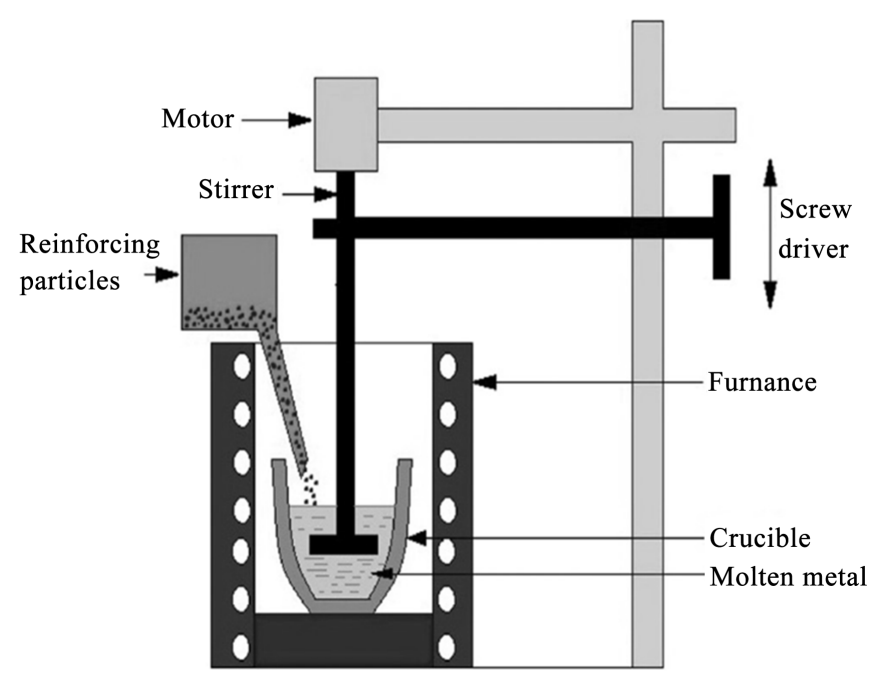

Figure 3. Diagram of stir casting set up. 
Experimental density is determined using the Archimedes principle by measuring the known volume of water displaced by the base alloy and composite specimens. The mass of the specimen is measured using a weighing balance (make: shimadzu-Electronic balance) of readability of 0.0001 grams.

$\rho=$ mass of the specimen/volume of water displaced

$$
\% \text { Porosity }=\frac{\rho_{t h}-\rho_{\exp }}{\rho_{t h}} \times 100
$$

From the values of density of base alloy and composite it is observed that density decreases with increase in reinforcement as shown in Figure 4. Porosity of the composite was found to increase with the reinforcement content (Figure 5). The increase in porosity is attributed to gas entrapment during mixing, shrinkage, and presence of air bubbles in the composite slurry.

\subsection{Hardness Test (Figure 6)}

Hardness is the ability of the material for indentation. Rockwell Hardness number of the bulk specimen of the base alloy and composites is measured using indentation of $1 / 16$ ' ball indenter under a load of $100 \mathrm{Kgf}$ for dwell time of 15 seconds. An average of values of readings obtained during the tests were taken and tabulated. The hardness was found to increase with increase in weight (\%) of zircon sand particles.
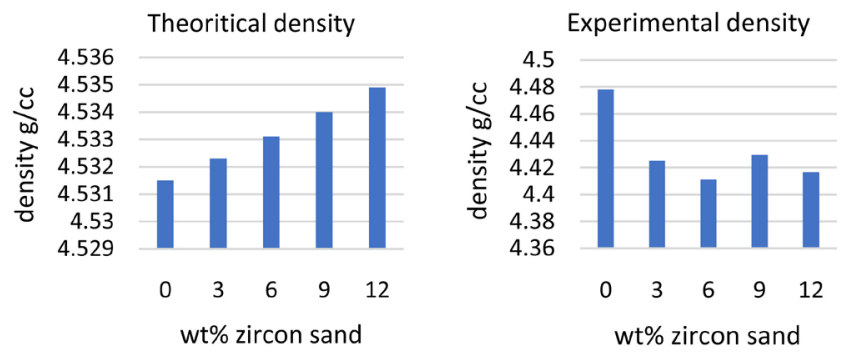

Figure 4. Variation of measure density with composition of reinforcement.

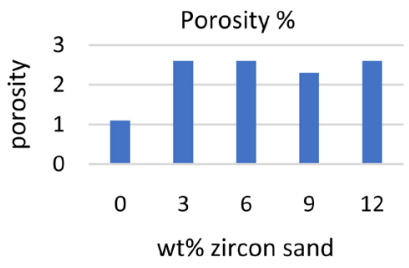

Figure 5. Porosity with increase in weight percentage of zircon sand.

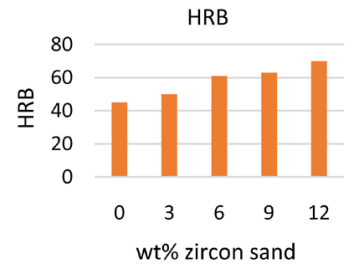

Figure 6. Brinell Hardness for the ZA-27 composite. 
The ZA27 alloy is strengthened due to solid solution strengthening, while the ZA27 composite is dispersion strengthened due to presence of zircon sand particulates in the zinc aluminum matrix. The hardness testing is compressive in nature and the area under the indentation is work hardened, resulting in enhanced values.

\subsection{Microstructure Studies}

When the Zinc alloy is solidified it results information of various phases like, $\alpha+$ $L, \beta, \alpha+\beta$ and $\alpha+\eta$ as shown in Figure 7 The microstructure in Figure 2(a) of ZA-27 alloy reveals the Aluminum rich matrix ( $\alpha$ FCC) and dendrite Zinc phase ( $\eta \mathrm{HCP}$ ), $\mathrm{CuZnO}_{4}$ at $382^{\circ} \mathrm{C}$ and $\mathrm{Al}_{4} \mathrm{Cu}_{3} \mathrm{Zn}$ at $275^{\circ} \mathrm{C}$ [11] (Figure 7, Figure 8 and Figure 9).

The wavelength of X-rays is in the range of $0.01 \mathrm{~nm}$ to $10 \mathrm{~nm}$ that can penetrate through the crystal structure to reveal the properties of material while exiting out of it. XRD is are used to characterize different types of materials. Interplanar spacing $(d)=$ Order of Reflection $(n) \times$ Wavelength $(\lambda) / 2 \times \sin \theta$ using Braggs law.

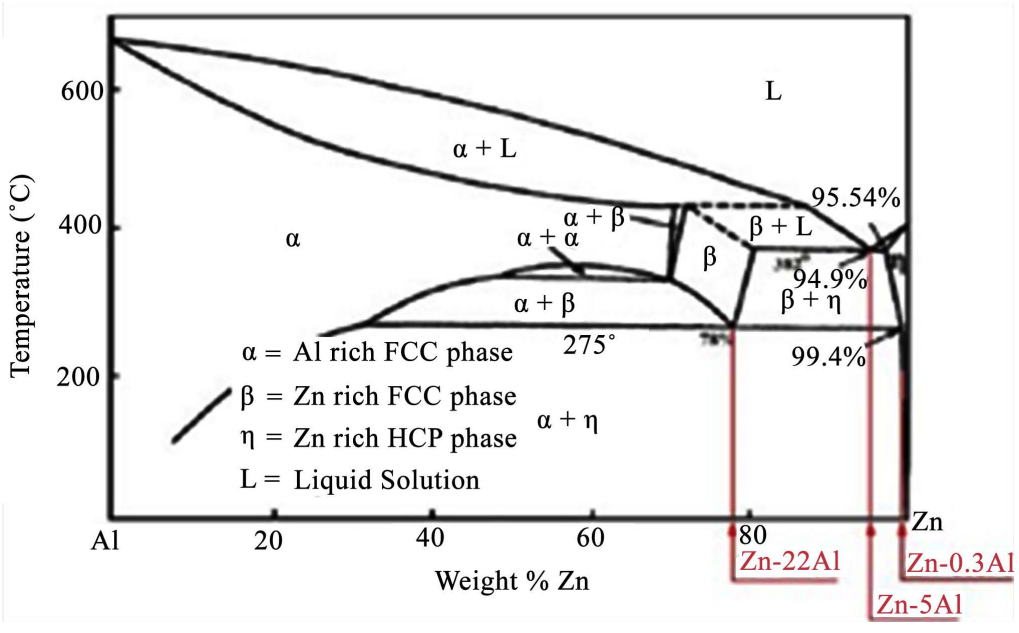

Figure 7. Phase diagram, of ZA-27 alloy.

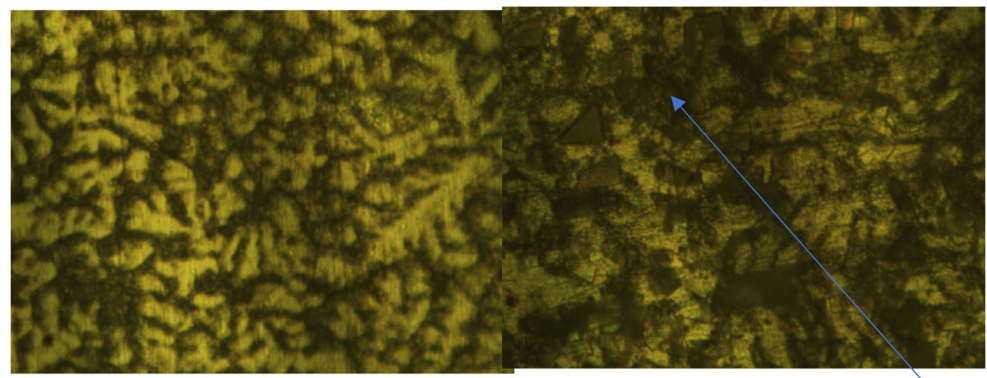

Zircon sand particles (tetragonal)

Figure 8. Optical microscope pictures of zircon sand reinforced ZA-27 (100× Magnification). 
Selected Area 1

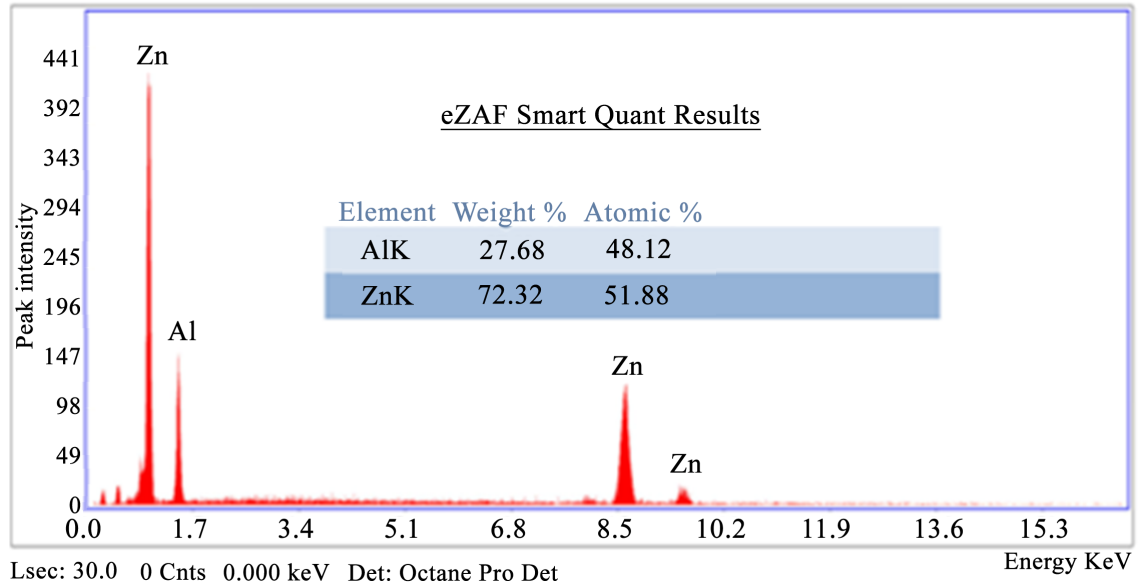

Figure 9. EDAX of ZA-27.

\subsection{SEM/EDAX Studies}

To study the morphology of the different composition of composites SEM (Make: TESCAN VEGA3) was used with EBSD arrangement attached with EDS detector. The micrographs reveal the presence of distribution of zircon particles and their distribution. The average size of the zircon sand particles is found to be 100 - 150 microns distributed in the matrix of ZA27 alloy and confirms the sieve analysis shown in Figure 2. The EDS detector confirms the existence of zinc, aluminum, zircon, and silicon along with the oxides due to chemical reactions at the interface.

Principle of Bragg's law is the basis for X-Ray diffraction. XRD is conducted to identify different phases present in the ZA27 composite samples using PAN-Analytical-Xpert ${ }^{3}$ powder XRD fitted with $\mathrm{Ni}$ filter operated at $30 \mathrm{~mA}$ and $40 \mathrm{kV}$ generator settings using $\mathrm{Cu}-\mathrm{k} \alpha$ radiation with a wavelength of $1.5418 \AA$. The diffraction angle $(2 \theta)$ range is varied from $20^{\circ}$ to $90^{\circ}$.

$\mathrm{XRD}$ of the zircon sand and composites confirmed the presence of elements like zircon, silicon, and oxygen in the reinforcement as shown in Figure 10. XRD of ZA-27 composites containing 3\% and $12 \%$ zircon sand reveals the presence of zirconium silicate and their compounds. The compounds are found at the interface of matrix and particles due to chemical reaction of Zinc aluminum with zircon sand (Figure 11, Figure 12 and Figure 14).

The presence of voids will bring down the strength of the composite developed. With increase in zircon sand reinforcement content there occurs agglomeration of particles because of which voids get accumulated during deformation. The agglomeration of particulates is undesirable in fabrication of metal matrix composites due to which strength of the fabricated composites certainly reduces. The strength is also obtained by good wetting of the zircon sand and ZA27 alloy, resulting in strong interface for efficient load transfer [12].

The bonding strength at the interface will affect the mechanical and physical properties like coefficient of thermal expansion, thermal conductivity, and 


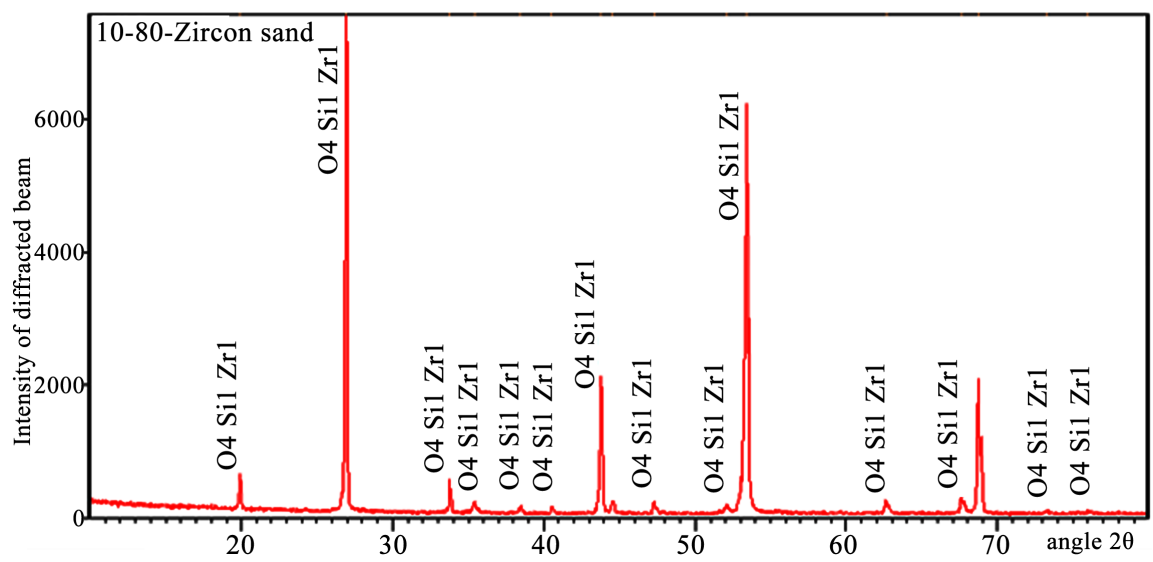

Figure 10. XRD of Zircon sand particles.

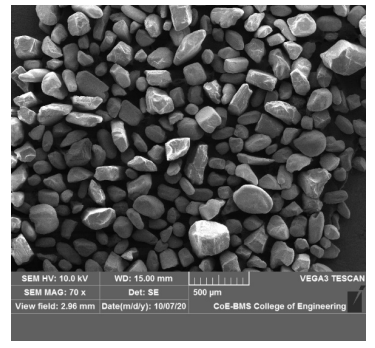

(a)

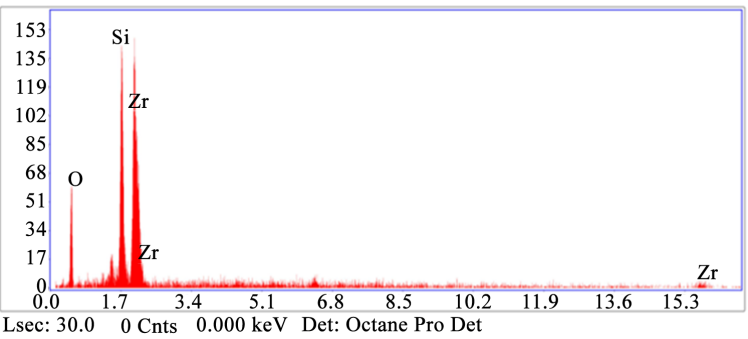

(b)

Figure 11. (a) SEM of Zircon sand particles (b) EDAX of Zircon sand particles.

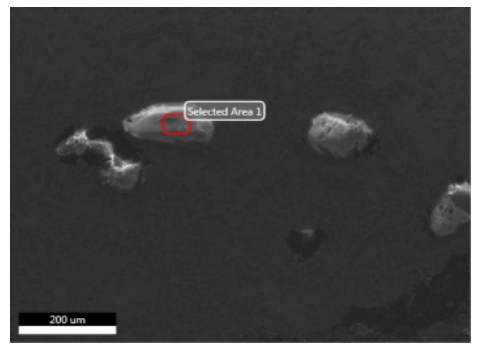

(a)

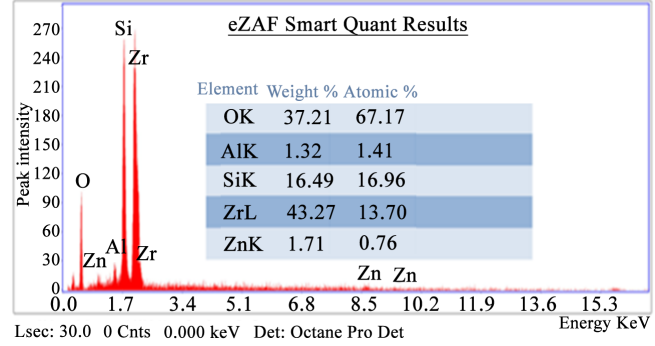

(b)

Figure 12. (a) SEM for ZA-27 composite containing zircon sand (b) EDAX for ZA-27 composite containing zircon sand.

damping. Coefficient of thermal expansion is a major criterion for the ZA27 composites with good dimensional stability. To obtain better interface characteristics there are process variables that need to be controlled such as processing technique, pouring temperature, stirring time, stirring speed etc. as well as reinforcement content and chemical properties of matrix and reinforcement [13].

It follows from SEM pictures in Figure 13 that the multiple microcracks observed in the regions of particle agglomeration will results in reduction in ductile region of the composite The addition of the hard zircon particles as reinforcement in the ductile soft ZA-27 alloy matrix results in resistance to deformation. Subsequently, causing triaxial stress state ZA27 matrix results in the formation of voids and growth in the matrix and also debonding at the interface of the particle 

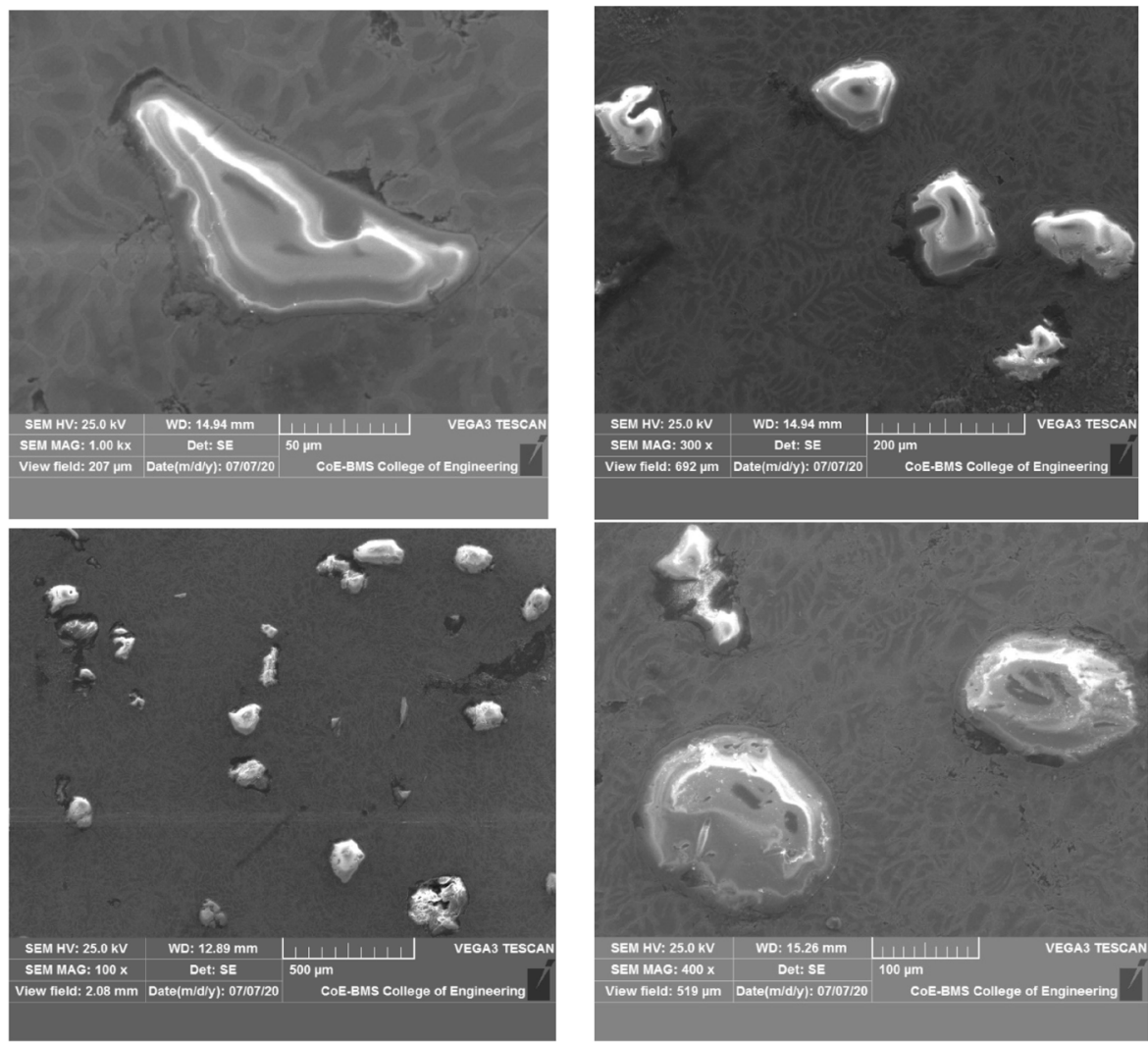

(a)
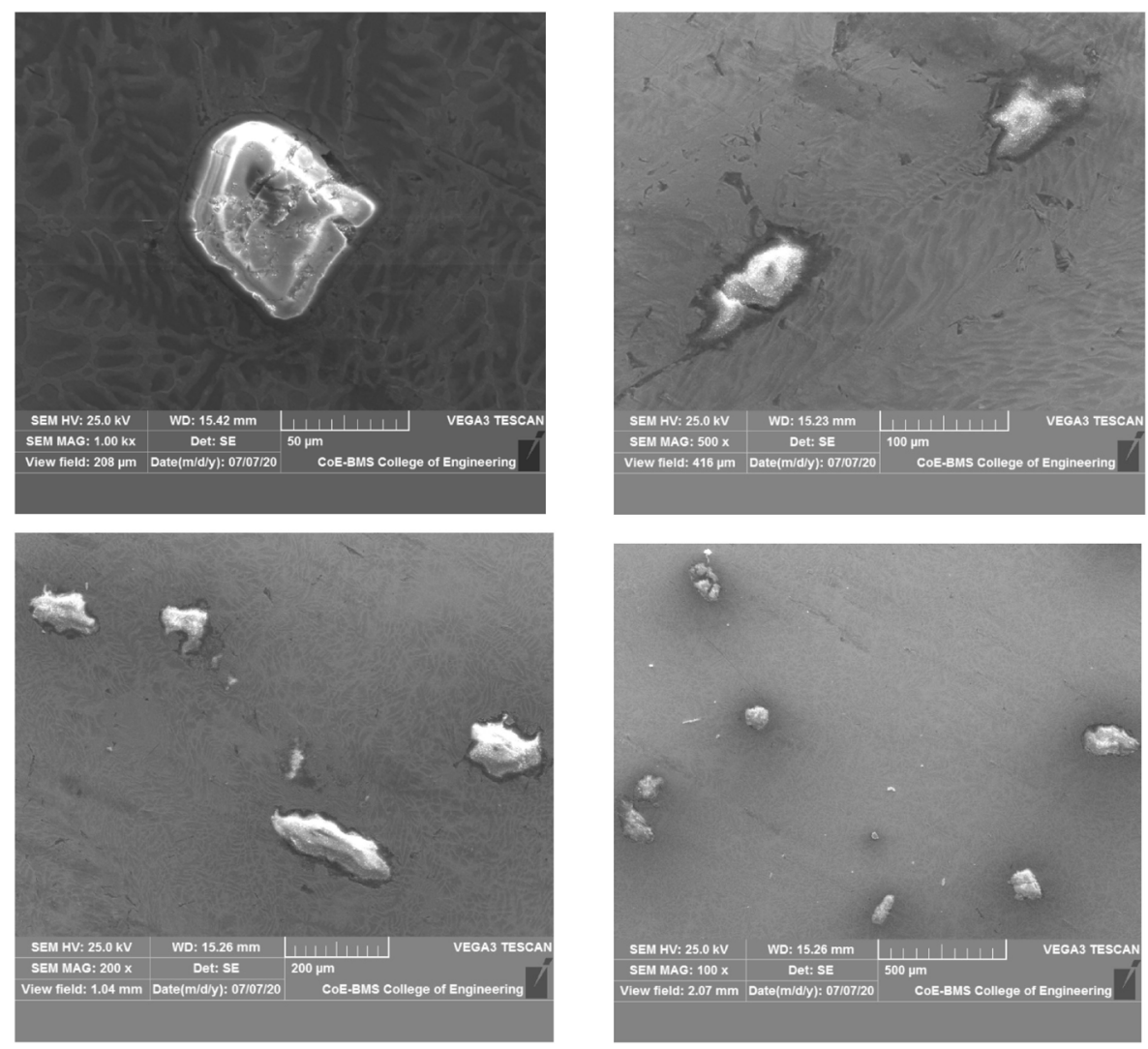

(b) 

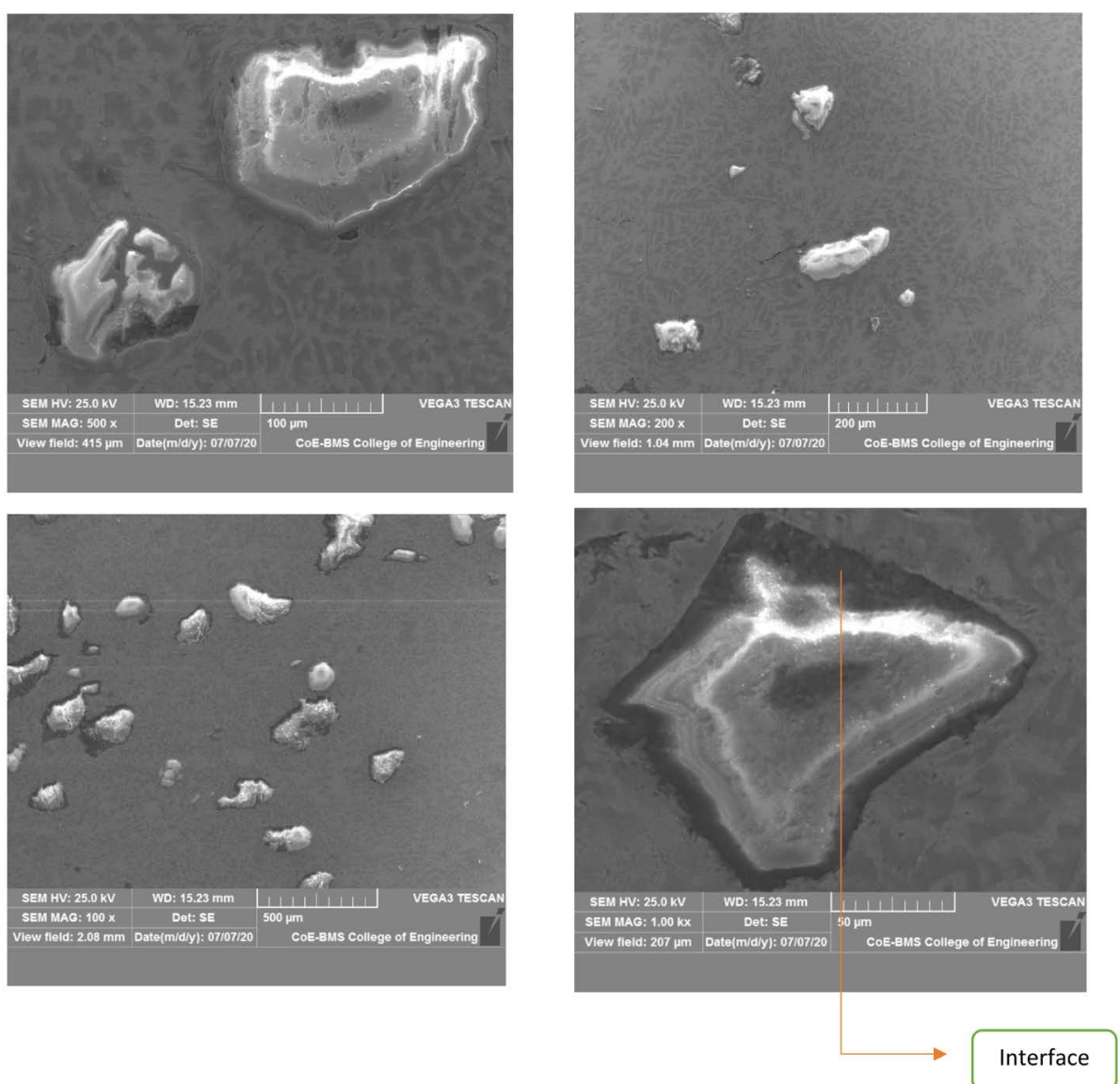

(c)
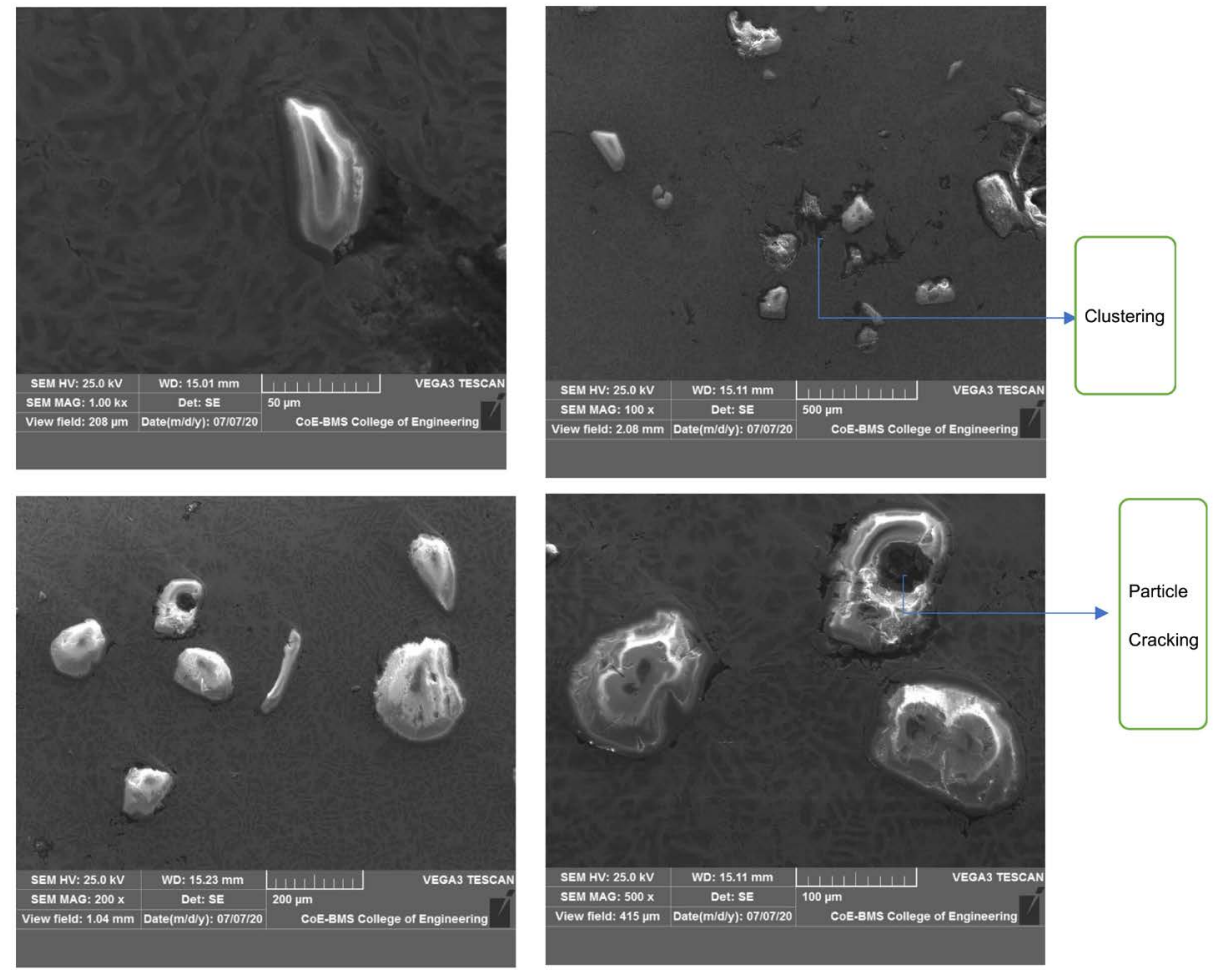

(d) 


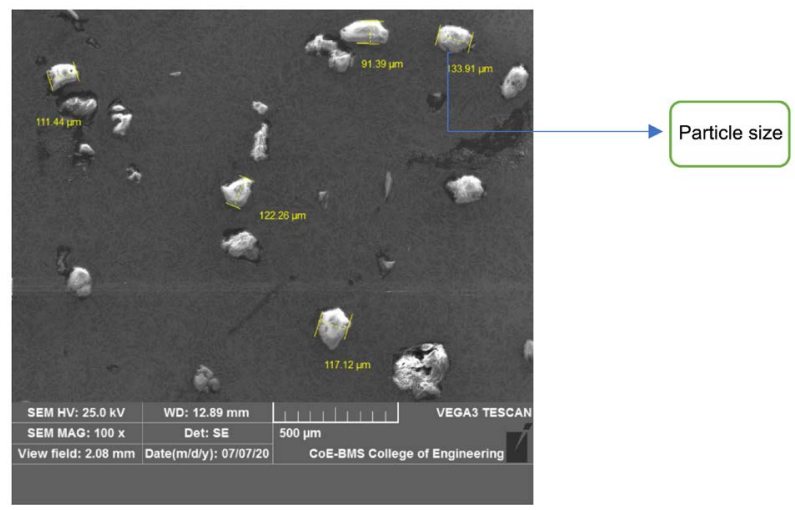

(e)

Figure 13. (a) SEM images of ZA27 composites of magnification $100 \times, 200 \times, 300 \times$, $1000 \times$ for $3 \mathrm{wt} \%$; (b) SEM images of ZA27 composites of magnification 100×, 200×, 300 $\times$, $1000 \times$ for $6 \mathrm{wt} \%$; (c) SEM images of ZA27 composites of magnification $100 \times, 200 \times, 300 \times$, $1000 \times$ for $9 \mathrm{wt} \%$; (d) SEM images of ZA27 composites of magnification 100×, 200×, 300×, $1000 \times$ for $12 \mathrm{wt} \%$; (e) Size of the particles distributed in ZA-27 alloy (Magnification: $100 \times)$.

and the matrix [12] Shrinkage cavities are seen in the micrographs due to porosity linking to reduction in strength of the composite. Hence, distribution of the particles is an important factor governing the behaviour of the composites. It is very essential to control particle clustering and voids to in the microstructure of the composite [6] (Figure 14).

Apart from the above challenges in processing of composites by liquid metallurgy route it is necessary to understand strong chemical bond that exists between reinforcement and matrix. It is very important to know the various advantages and limitations of fabrication techniques like liquid metallurgy, powder metallurgy, spray deposition or in-situ route of preparation of composites. Also, due consideration to be given to the disparity in the physical properties of Zircon sand as reinforcement and ZA27 matrix in order to obtain a satisfactory interface between the reinforcement and matrix [14]. Large differences in the coefficients of thermal expansion in the reinforcement and matrix lead to the formation of residual stresses in the composite during the fabrication process.

\subsection{Dislocation Density of the Composite Due to Difference in CTE}

Dislocation density is total length of dislocation to volume of the crystal. It is well known that microscopic movement of dislocation will be having significant effect on the macroscopic deformation of materials. Effect of ceramic particles present in ductile alloy matrix on strength and hardness has been studied earlier [15] by theories like, quench strengthening, Orowan strengthening, work hardening, grain strengthening/Hall Petch mechanism of the composites. During solidification and cooling of composite to room temperature if the particle-reinforcement interface bonding is good then tensile and compressive stresses is developed in ZA27 alloy and zircon sand particles, respectively. Because of large difference of coefficient of thermal expansion (CTE) and temperature 
Selected Area 1

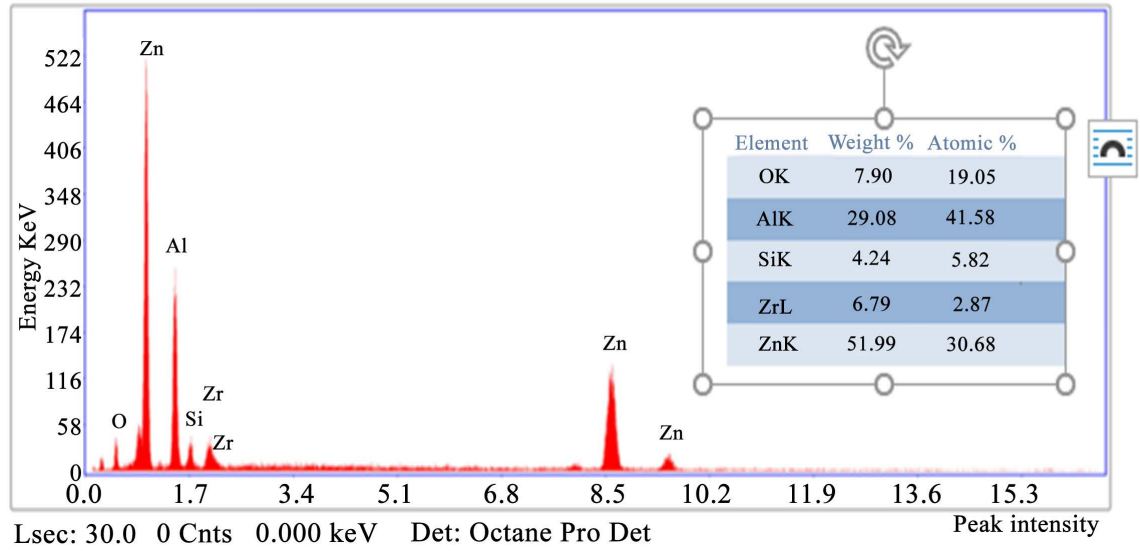

Figure 14. EDAX conforming the presence of reinforcement.

difference $(\Delta T)$ due to cooling of composites, plastic deformation of ZA27 alloy matrix is likely to occur in order to accommodate elastic residual stress that forms in matrix, CTE mismatch will be large at interface due to work hardening setting up dislocations formed during cooling of composite whose movements are arrested at particle and matrix interface and exhibits large hardness which decreases with increasing distance from interface. This is due to high density of dislocation at the interface and can be predicted using the model of [15] The dislocation density of particulate composite at the interface is given by Equation (3) where $b=0.26 \mathrm{~nm}$ burgers vector for zinc alloy [15] $d=$ particle size.

$$
\rho=\frac{12 \Delta C \Delta T V_{p}}{b d\left(1-V_{p}\right)}
$$

Themal mismatch strain,

$$
\Delta C=\alpha_{m}-\alpha_{p}
$$

$\Delta T=$ Temperature difference during cooling of casting from solidus temperature.

It is understood that coefficient of thermal expansion of the composites depends on several material parameters like the composition, the microstructure of the matrix, the reinforcement volume fraction and distribution as well as residual stresses formed due to the CTE mismatch, porosity, volume fraction, and the interface strength [16].

Thermo-elastic models like Kerner and Turner have been used to understand the behavior of thermal expansion of composites. It is important to note that these models can predict the CTE relying on the reinforcement content and elastic nature of the matrix [16] [17], however, they do not take into account the case of plasticity of the matrix nor the voids formed in the composites [18].

By Rule of mixture CTE $(\alpha)$ of composites are calculated using,

$$
\alpha_{c}=\alpha_{p} V_{p}+\alpha_{m} V_{m}
$$

Based on Turner model, 


$$
\alpha_{c}=\frac{\alpha_{m} K_{m} V_{m}+\alpha_{p} K_{p} V_{p}}{K_{m} V_{m}+K_{p} V_{p}}
$$

Based on Kerner's model.

$$
\alpha_{c}=\alpha_{m} V_{m}+\alpha_{p} V_{p}+V_{m} V_{p}\left(\alpha_{p}-\alpha_{m}\right) \times \frac{K_{p}-K_{m}}{V_{m} K_{m}+V_{p} K_{p}+\frac{3 K_{m} K_{p}}{4 G_{m}}}
$$

where, $\alpha, E, G, K, V$ are CTE, Youngs modulus, Shear modulus, bulk modulus, and volume fraction, respectively. Subscripts $m, p, c$ indicates matrix, particles, and composites.

The Bulk modulus of the material is calculated using,

$$
K=\frac{E}{3\left(3-\frac{E}{G}\right)}
$$

It is important to understand the mechanism of the reduction in CTE values in the ZA27 composites due to presence of voids. From Table 3 it is found the CTE and elastic modulus of the reinforcement are lower and higher than those of matrix resin, respectively. When this composite is subjected to temperature rise, Thermal mismatch strain, $\Delta C=\alpha_{m}-\alpha_{p}$ is induced. This mismatch strain initiates the formation of compressive and tensile stress in the matrix and reinforcement (Table 4 and Table 5, Figure 15 and Figure 16).

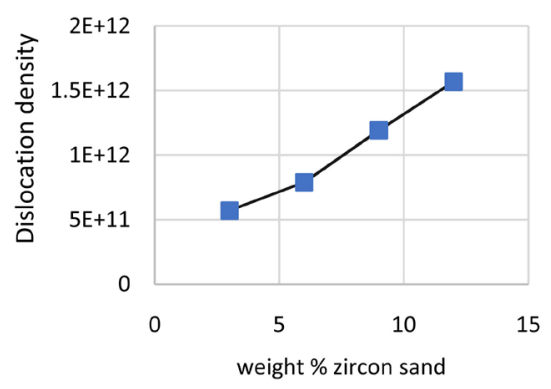

Figure 15. Variation of dislocation density vs weight percent of zircon sand.

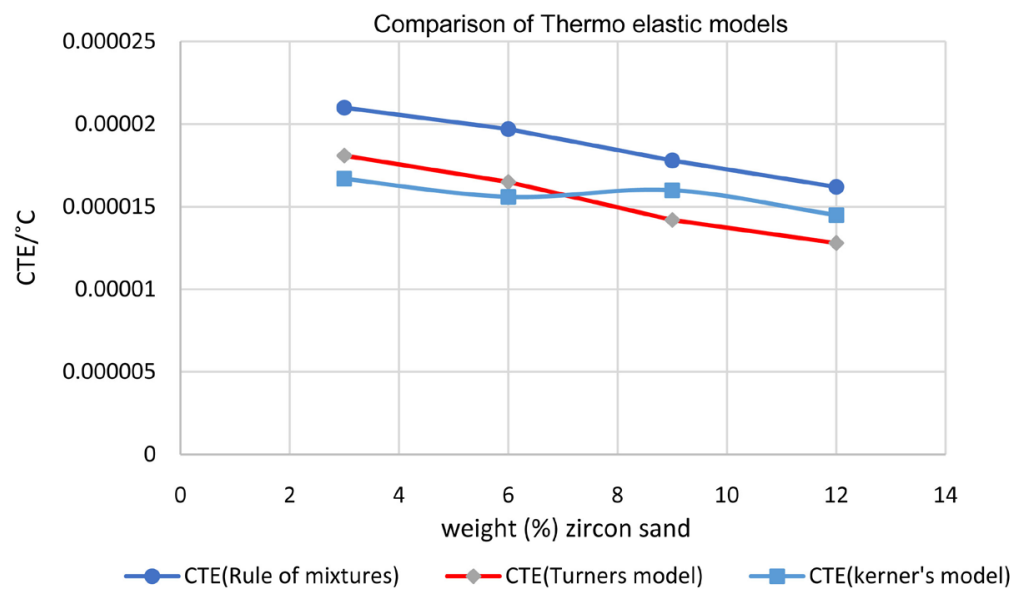

Figure 16. CTE comparison of composite using by thermoelastic models. 
Table 3. Elastic constants and CTE of ZA27 and zircon sand.

\begin{tabular}{ccccc}
\hline Material & $E \mathrm{GPa}$ & $G \mathrm{Gpa}$ & $K \mathrm{Gpa}$ & $\mathrm{CTE} /{ }^{\circ} \mathrm{C}$ \\
\hline ZA27 & 77 & 31 & 49.7 & $26 \times 10^{-6}$ \\
Zircon sand & 97.1 & 36.5 & 95.27 & $4.5 \times 10^{-6}$ \\
\hline
\end{tabular}

Table 4. Results of dislocation density.

\begin{tabular}{cccc}
\hline Slmo. & Sample & Weight (\%) zircon sand & Dislocation density $(\rho)$ \\
\hline 1 & A & 0 & - \\
2 & B & 3 & $5.69 \times 10^{11}$ \\
3 & C & 6 & $7.89 \times 10^{11}$ \\
4 & D & 9 & $1.19 \times 10^{12}$ \\
5 & E & 12 & $1.57 \times 10^{12}$ \\
\hline
\end{tabular}

Table 5. Comparison of CTE values using thermo elastic models.

\begin{tabular}{cccccc}
\hline Sl No & Sample & $\begin{array}{c}\text { Weight (\%) } \\
\text { zircon sand }\end{array}$ & $\begin{array}{c}\text { CTE } \\
\text { (Rule of mixtures) }\end{array}$ & $\begin{array}{c}\text { CTE } \\
\text { (Turners model) }\end{array}$ & $\begin{array}{c}\text { CTE } \\
\text { (Kerner's model) }\end{array}$ \\
\hline 1 & A & 0 & - & - & - \\
2 & B & 3 & $2.10 \times 10^{-5}$ & $1.81 \times 10^{-5}$ & $1.67 \times 10^{-5}$ \\
3 & C & 6 & $1.97 \times 10^{-5}$ & $1.65 \times 10^{-5}$ & $1.56 \times 10^{-5}$ \\
4 & D & 9 & $1.78 \times 10^{-5}$ & $1.42 \times 10^{-5}$ & $1.60 \times 10^{-5}$ \\
5 & E & 12 & $1.62 \times 10^{-5}$ & $1.28 \times 10^{-5}$ & $1.45 \times 10^{-5}$ \\
\hline
\end{tabular}

If micro voids are dispersed in the matrix, they are subjected to the compressive stresses, resulting in the shrinkage of the void volume. Hence, the overall CTE of the ZA27 composite is reduced and shape of the voids results CTE reduction. The reduction of CTE values of the composite is also due to low volume fraction of the matrix and existence of voids in the composite. Hence, the ZA27 matrix, with large CTE value is reduced with increase of volume fraction of voids, affecting the overall CTE value of ZA27 composites [7] [8] [16].

If the interface between zircon sand and matrix of ZA27 is good, then a significant amount of the reduction of CTE value of the composite occurs. However, it is more likely that these high thermal stress values induce fracture at the interface. So the compressive thermal stress, which is the main driving force of the composite CTE reduction due to voids, is relaxed in this respect so that the effect of voids on CTE values are reduced [13].

\section{Conclusions}

The experimental density is reduced with increase in weight fraction of zircon sand and the bulk hardness of the ZA27/zircon composite prepared by stir casting route is found the increase with increase in zircon sand reinforcement. The Optical microscopy studies of the ZA27/zircon composites and microstructure 
obtained from SEM/EDAX and XRD studies indicate the presence and distribution of zircon sand particles and intermetallic compounds in the ZA27 matrix along with agglomeration.

The SEM pictures also show the presence of voids and particle clustering in the matrix. The role of particle-matrix interface as revealed from the microstructure of the composite is studied to understand the thermal expansion behavior of composites. Strengthening of composites due to mechanism of dislocation density is obtained analytically.

From the analytical results obtained by the rule of mixtures it is found that the value of CTE decreases with the increase in zircon sand reinforcement. The values are closely predicted by thermoelastic energy principles like Turners and Kerner's model using Equation (6) and Equation (7) in comparison to rule of mixtures Equation (5). The reason for decrease in CTE values is due to the presence of voids and agglomeration during the fabrication of the ZA27 MMC.

The dislocation density is found to increase with the increase in reinforcement content and depicts the inverse relation with CTE values. Thermoelastic models reveal that Zircon sand particles as reinforcement is affecting the augmentation of strength of the composites due to increase in dislocation density arising out of large difference in CTE values during solidification of the composites. But it does not consider casting defects like voids or poor interface between ZA27matrix and Zircon sand particulates.

\section{Acknowledgements}

All acknowledgments (if any) should be included at the very end of the paper before the references and may include supporting grants, presentations, and so forth.

\section{Conflicts of Interest}

The authors declare no conflicts of interest regarding the publication of this paper.

\section{References}

[1] Babić, M. and Ninković, R. (2004) Zn-Al Alloys as Tribomaterials. Tribology in Industry, 26, 3-7.

[2] Babić, M., Ninković, R., Mitrović, S., et al. (2007) Influence of Heat Treatment on Tribological Behavior of Zn-Al Alloys. Tribology in Industry, 29, 23-31.

[3] Shiva Kumar, N. (2018) Mechanical and Wear Behavior of ZA-27/Sic/Gr Hybrid Metal Matrix Composites. Materials Today Proceedings, 5, 19969-19975. https://doi.org/10.1016/j.matpr.2018.06.363

[4] Hemanth Kumar, T.R., Swamy, R.P. and Chandrashekar, T.K. (2013) An Experimental Investigation on Wear Test Parameters of Metal Matrix Composites Using Taguchi Technique. Indian Journal of Engineering and Materials Sciences, 20, 329-333.

[5] Fatile, B.O., Adewuyi, B.O. and Owoyemi, H.T. (2017) Synthesis and Characteriza- 
tion of ZA-27 Alloy Matrix Composites Reinforced with Zinc Oxide Nanoparticles. Engineering Science and Technology, 20, 1147-1154.

https://doi.org/10.1016/j.jestch.2017.01.001

[6] Sharma, S.C., Girish, B.M., Somashekar, D.R., et al. (1999) Mechanical Properties and Fractography of Zircon-Particle-Reinforced ZA-27 Alloy Composite Materials. Composites Science and Technology, 59, 1805-1812.

https://doi.org/10.1016/S0266-3538(99)00040-8

[7] Panwar, R.S. and Pandey, O.P. (2013) Study of Wear Behavior of Zircon SandReinforced LM13 Alloy Composites at Elevated Temperatures. Journal of Materials Engineering and Performance, 22, 1765-1775.

https://doi.org/10.1007/s11665-012-0383-0

[8] Shoba, C., Ramanaiah, N. and Rao, D.N. (2014) Ageing Behavior of Aluminum Hybrid Metal Matrix Composites. Materials Science: An Indian Journal, 3, 79-85.

[9] Prasad, D.S., Shoba, C. and Ramanaiah, N. (2014) Investigations on Mechanical Properties of Aluminum Hybrid Composites. Journal of Materials Research and Technology, 3, 79-85. https://doi.org/10.1016/j.jmrt.2013.11.002

[10] Ramesha, V., Prasad, T.B., Nayak, V. And Neelakantha, V.L. (2018) A Study on Mechanical Properties of Al-17Si Metal Matrix Composites. IOP Conference Series: Materials Science and Engineering, 376, 012100. https://doi.org/10.1088/1757-899X/376/1/012100

[11] Gurunagendra, G., Ravishankar, T.N., Ravikeerthi and Raju, B.R. (2019) Dry Sliding Wear Studies of Zinc Aluminium Alloy Containing Micro and Nano Solid Lubricants. International Journal of Engineering Research and Advanced Technology, 5, 7-13. https://doi.org/10.31695/IJERAT.2019.3457

[12] Madhusudan, S., Sarcar, M.M.M. and Rao, N.B.R.M. (2016) Mechanical Properties of Aluminum-Copper(p) Composite Metallic Materials. Journal of Applied Research and Technology, 14, 293-299. https://doi.org/10.1016/j.jart.2016.05.009

[13] Mitra, R. and Mahajan, Y.R. (1995) Interfaces in Discontinuously Reinforced Metal Matrix Composites: An Overview. Bulletin of Materials Science, 18, 405-434. https://doi.org/10.1007/BF02749771

[14] Chappell, P.J.C. (1990) Reinforcement-Matrix Interface Effects in Metal Matrix Composites. MRL Technical Note, MRL-TN-562.

[15] Miller, W.S. and Humphreys, F.J. (1991) Strengthening Mechanisms in Particulate Metal Matrix Composites. Scripta Metallurgica et Materialia, 25, 33-38.

https://doi.org/10.1016/0956-716X(91)90349-6

[16] Hatta, H., Takei, T. and Taya, M. (2000) Effects of Dispersed Microvoids on Thermal Expansion Behavior of Composite Materials. Materials Science and Engineering: $A, 285,99-110$. https://doi.org/10.1016/S0921-5093(00)00721-8

[17] Bharat, V., Prasad, B.D. and Venkateswarlu, K. (2017) Effect of Beryllium Aluminum Cyclosilicate on Thermal Expansion Behavior of Al-Based Composites. Journal of Minerals and Materials Characterization and Engineering, 5, 140-152.

https://doi.org/10.4236/jmmce.2017.53012

[18] Nam, T.H., Requena, G. and Degischer, P. (2008) Thermal Expansion Behaviour of Aluminum Matrix Composites with Densely Packed SiC Particles. Composites Part A: Applied Science and Manufacturing, 39, 856-865.

https://doi.org/10.1016/j.compositesa.2008.01.011 